UDC: $316.77: 008$

https://doi.org/10.18485/akademac_sdt.2020.1.ch7

\title{
MEDIJI KAO PROMOTERI (NE)MATERIJALNE KULTURNE BAŠTINE
}

Andrea Ratković

\section{Sažetak}

U okviru ovog rada sprovodi se kritičko promišljanje medija kao promotera (ne) materijalne kulturne baštine i to iz perspektive društveno-humanističkih nauka s naglašenim interdisciplinarnim pristupom. Teorijski osvrt na medije u savremenom društvenom kontekstu, a potom izdvajanje nekih od ključnih teorijskih postavki koje u svom fokusu imaju fenomen kulture treba da posluže kao osnova za dalje preispitivanje odnosa medija i kulturne baštine, ali i za (re)definisanje uloge medija u promociji i popularizaciji iste. Završni deo rada zamišljen je kao iskorak iz teorije i interdisciplinarnih polemika u jedan vid studije slučaja koja markira i razmatra neke od segmenata (ne)materijalnog kulturnog nasleđa Sremskih Karlovaca, a uz apostrofiranje medija kao njihovih (in)direktinih i produktivnih promotera. Namera je da se, između ostalog, skrene pažnja ne samo stručnoj, već i široj javnosti na višestruke benefite koji proizilaze iz nadogradnje odnosa između medija i kulturne baštine, a uz posebno izdvajanje medijskog i kulturnog zaokreta.

Ključne reči: mediji, kultura, baština

\section{MEDIA AS PROMOTERS OF MATERIAL AND IMMATERIAL CULTURAL HERITAGE}

\begin{abstract}
This paper examines the role of media in the promotion and popularization of culture in our daily lives. The author of this paper conducts critical analyses of the role of media as a promoter of material and immaterial cultural heritage while following an interdisciplinary approach. The theoretical study of media in
\end{abstract}

1 Fakultet savremenih umetnosti u Beogradu, Centar za afirmaciju slobodne misli u Sremskim Karlovcima, e-mail: andrearatkovic08@gmail.com 
the contemporary social context and the selection of key theoretical ideas about culture should serve as a starting point for further review of the relationship between media and heritage as well as for (re)defining the roleof media in cultural promotion. The final part of the paper has been conceived as a step out of theory and interdisciplinary polemics, and it contains a case study that considers some segments of the material and immaterial cultural heritage of Sremski Karlovci. The author's intention is to draw attention to the numerous benefits that arise from upgrading the relationship between media and cultural heritage.

Keywords: media, culture, heritage

\section{UVODNE NAPOMENE}

Imajući u vidu opšte društvene (ne)prilike, čini se da kultura danas prolazi kroz krajnje problematične metamorfoze koje za svoj ishod imaju njenu redukciju, degradaciju i/ili marginalizaciju. Naime, na mesto istinske kulture tj. kulture $u$ pravom smislu te reči sve češće dolaze najrazličitije pseudokulture kao krajnje upitni socio-kulturni derivati. Pomenute pseudokulture mogu se, između ostalog, posmatrati kao pojedinačni aspekti masovne kulture čija uloga u konstituisanju opšte slike stvarnosti nije ni malo zanemarljiva. Stvarajući i promovišući izrazito snažne modele identifikacije, masovna kultura istovremeno afirmiše specifične obrasce mišljenja i postupanja koji se kao takvi u velikoj meri negativno odražavaju po njoj svojstveno društvo i njime obuhvaćene društvene subjekte. Tome treba dodati i da pomenuta kultura učestvuje u zasnivanju više nego upitnih vrednosnih sistema, a što se odražava na nestanak starih i formiranje novih "kulturnih elita“, „kulturnih autoriteta“, ",kulturnih paradigmi“ itd. Sve ovo se neminovno odražava i na kulturnu baštinu kao naročito značajan segment istinske kulture, te tako danas svedočimo kontinuiranim i sistematskim (zlo)upotrebama baštine, a za potrebe promocije i popularizacije onih društvenih normi i načela iza kojih stoje vodeće interesne grupacije.

Stoga ne treba da čudi što se u savremenoj teoriji, pored nastojanja da se ponudi što sveobuhvatnije određenje kulture (u nameri da se skrene pažnja na svu njenu kompleksnost), veliki deo napora ulaže u markiranje i ekspliciranje svega onog što kultura nije. Naročita pažnja se posvećuje i promišljanju relacija između kulture i onih društvenih fenomena koji mogu bitno da utiču na društvene subjekte i njihovu recepciju kulture i njenih činilaca. Pri tome, posebno problematičnim 
se smatraju fenomeni koji svojim delovanjem ne doprinose opštem društvenom dobru, te samim time ni negovanju i daljem razvoju istinske kulture. S tim u vezi, u nastavku teksta fokus će biti na medijima kao izuzetno uticajnoj društvenoj pojavi koja ne samo da stoji u relaciji sa kulturom, već u velikoj meri ima udela u njenom (pre)oblikovanju². Naime, ono što je važno naglasiti jeste da mediji neretko imaju udela ne samo u marginalizaciji, već i u degradaciju onoga što se smatra kulturom u pravom smislu te reči, a kao posledica njihovih (zlo)upotreba u cilju promocije i popularizacije širokog spektra pseudokultura. Iz tog razloga, savremene mainstream medijske prakse koje za svoj ishod imaju mnoštvo negativnih implikacija po socio-kulturnu sferu treba markirati kao naročito problematične. Međutim, njihova kritika je više nego neosnovana ukoliko se koristi kao osnova za izvođenje konstatacija koje se u svojoj osnovi svode na kvalifikaciju medija kao $a$ priori negativnih pojava. Samim tim, svrha ovog rada jeste da kroz kritiku upitnih medijskih praksi ponudi smernice za njihovu dekonstrukciju i supstituciju, a radi afirmacije istinske kulture i njome obuhvaćenih vrednosti.

Nadalje, kritičko promišljanje medija kao promotera kako kulture uopšte tako i (ne)materijalne baština kao njenog bitnog segmenta predstavlja pokušaj skretanja pažnja ne samo stručnoj, već i široj javnosti na višetruke benefite koji proizilaze iz nadogradnje odnosa između medija i kulture (samim time i baštine), a uz posebno izdvajanje medijskog i kulturnog zaokreta. Teorijski osvrt na medije u savremenom društvenom kontekstu, a potom izdvajanje nekih od ključnih teorijskih postavki koje u svom fokusu imaju fenomen kulture poslužiće kao osnova za dalje preispitivanje odnosa medija i kulturne baštine, ali i za (re)definisanje uloge medija u promociji i popularizaciji iste. Završni deo rada zamišljen je kao iskorak iz teorije i interdisciplinarnih polemika u jedan vid studije slučaja koja će markirati i razmotriti neke od segmenata (ne)materijalnog kulturnog nasleđa Sremskih Karlovaca, a uz apostrofiranje medija kao njihovih (in)direktinih i produktivnih promotera.

2 O medijima i njihovom uticaju na socio-kulturni diverzitet, oblikovanje socio-kulturnih identiteta i (re)interpretiranje kulturnih konteksta bavila sam se u sledećim radovima: „Ideologizovani mediji i socio-kulturni diverzitet" (Interkulturalnost, br. 10, Zavod za kulturu Vojvodine, Novi Sad, 2015, str. 43-58), "Uloga medija u afirmaciji ideologizovanih socio-kulturnih identiteta“ (Socijalne (de)konstrukcije identiteta, Centar za afirmaciju slobodne misli, Sremski Karlovci, 2015, str. 129-143), "Medijske (re)interpretacije kulturnog konteksta i njihov uticaj na homogenizaciju društvenih odnosa“" (Konteksti, Filozofski fakultet, Novi Sad, 2015, str. 103-120), „Interkulturalnost i (ne)moć instrumentalizovanih medija“" (Interkulturalnost, br. 17, Kulturni centar Vojvodine, Novi Sad, 2019, str. 59-67). 


\section{Osvrt na društveni uticaj i efekte medije}

Knjige, novine, film, radio, televizija, Internet - samo su neki od medija koji imaju uticaj na konstituisanje čoveka kao društvenog subjekta. Upravo iz tog razloga život čoveka u savremenom socio-kulturnom kontekstu čini se gotovo nezamislivim bez medija. Pored očigledne razlike u uticaju koja danas postoji između tradicionalnih i novih medija, značajna je razlika i u samom stepenu uticaja medija na čoveka s početka XX i čoveka s početka XXI veka. Utisak koji se neminovno nameće jeste da se savremeni čovek do te mere oslanja na medije da je uspostavio neku vrstu zavisnog odnosa prema istima, te na taj način u bitnoj meri (ne)svesno redukovao sopstvene potencijale. Fidler konstatuje da "danas, ljudi rutinski mešaju i kombinuju mnoge oblike medija kako bi zadovoljili svoje potrebe, i ne misle mnogo o tome ${ }^{\prime \prime}$, te dodaje da "uprkos čestim žalbama na medijsku prenatrpanost, naša očekivanja trenutne komunikacije i stalne zabave neprekidno rastu" ${ }^{\prime \prime}$. Na taj način sposobnost simultanog praćenja i korišćenja više različitih medija izgleda da se razvija sa svakom novom generacijom, dok potencijali poput strpljenja, koncentracije, pamćenja, samostalnog (kritičkog) mišljenja itd. sve više opadaju.

Među (nus)pojavama medijskih praksi posebno se izdvajaju promene u načinima čovekove socijalizacije, (ko)egzistencije, kao i u obrascima čovekovog (samo)definisanja. Kada je reč o potonjem, potrebno je istaći da novi mediji pružaju čoveku mogućnost da bude šta god poželi i da se u skladu sa time prezentuje na način koji ne mora da ima nikakve veze sa onim što on u stvarnosti zaista jeste. Reč je o direktnoj posledici mogućnosti samih medija da predstave ne samo jedan segment stvarnosti, nego i da odu korak dalje time što će predstaviti svoje viđenje te iste stvarnosti. Naime, sprovodeći selekciju događaja i ličnosti o kojima će izveštavati i određujući karakter svojih sadržaja mediji donose sopstvenu viziju stvarnosti koja se, prema Bodrijaru, ne može posmatrati nikako drugačije do kao nova realnost ili simulakrum. Tehničko-tehnološki napredak i konzumerizam doveli su, prema ovom teoretičaru, do razdvajanja nekada prirodne veze između znakova i stvarnosti, odnosno do ukidanja jasne razlike između realnosti i njenog privida. Tako je medijska istina postala preovladavajući (neretko i jedini) pogled na svet recipijenata medijskih proizvoda. Prikazano u medijima doživljava se kao realnost budući da su upravo medijske simulacije zadobile primat u odnosu stvarnost. Prema Bodrijaru, „ono što celokupno jedno društvo nastoji neprekidno da proizvede i da reprodukuje, to je vaskrsavanje stvarnog koje mu izmiče", te

3 Fidler, R. (2004). Mediamorphosis: razumevanje novih medija. Beograd: Clio, str. 156.

4 Ibidem, str. 157. 
se iz tog razloga "svugde hiperrealizam simulacije ispoljava putem halucinantne sličnosti stvarnog sa samim sobom" ${ }^{\prime \prime}$.

Svet (novih) medija pokazao se kao konstitutivan za shvatanje same stvarnosti, te je tako i čovekovo poimanje realnosti pod uticajem tih istih medija bitno promenjeno. Drugim rečima, poimanje stvarnosti doživelo je transformaciju time što je mišljeno kao per definitionem medijski isposredovano. To, prema mišljenju Divne Vuksanović, ne znači da je „prvobitno shvaćena realnost, kako su je definisali stari metafizičari, neposredno potisnuta i ukinuta ovom drugom, medijskom stvarnošću, pošto bi takav zaključak bio izlišan i krajnje pojednostavljen", ali „ima osnova za tvrdnju da se pojavom i učestalom 'kreativnom' upotrebom, pre svega, medija masovnih komunikacija, u današnjem vremenu doživljaj realnosti u velikoj meri izmenio" ${ }^{\text {. }} \mathrm{S}$ tim u vezi, bitno je naglasiti da su sa promenama $u$ doživljaju realnosti neminovno nastupile i promene u doživljaju kulture, kao i baštine. Preciznije, medijima posredovana kultura je, pre svega, pseudokultura koju karakteriše važnost medijske reprezentacije, prolaznost, kratkotrajnost i promenljivost, te koja ne samo da negira uspostavljanje bilo koje trajne strukture, nego čak negira i samu stvarnost. Reč je o kulturi u krajnje ograničenom smislu koja je upućena na tehnologiju i koja poseduje izuzetno razvijene sposobnosti za brzo odbacivanje starog i još brže prihvatanje novog.

Iz rečenog proizilazi da pitanja koja se odnose na mesto i ulogu istinske kulture za savremenog čoveka ne gube na svojoj aktuelnosti, već da su, naprotiv, od naročitog značaja za kritičko sagledavanje medijima prožete, kao i bitno (pred) određene čovekove stvarnosti. U savremenom socio-kulturnom kontekstu gde gotovo svako zahvaljujući tehničko-tehnološkim dostignućima može da bude ono što poželi i da se predstavi u skladu sa sopstvenim željama, primat zauzima više nego problematična masovna, potrošačka, fabrikovana i instant kultura. Ona se kao takva negativno odražava kako po samo društvo tako i po njime obuhvaćene subjekte, a jedna od njenih više nego očiglednih konsekvenci jeste potiskivanje kulture u pravom smislu te reči. Iz tog razloga, gotovo minimalna upotreba medija u svrhu promocije istinske kulture, te sve otvorenije zloupotrebe tih istih medija u cilju nametanja najrazličitijih pseudokultura ne sme da se ignoriše jer bi u suprotnom ishodi ovakvih praksi bili krajnje devastirajući.

O tome koliko je važno da se istraje u nastojanjima da se (re)definiše uloga medija u svrhu postizanja ne samo medijskog, već i kulturnog zaokreta, biće mnogo jasnije nakon što se iznova promisli fenomen kulture, te njegov značaj za

5 Bodrijar, Ž. (1991). Simulakrumi i simulacija. Novi Sad: Svetovi, str. 26-27.

6 Vuksanović, D. (2007). Filozofija medija: ontologija, estetika, kritika, Beograd: Fakultet dramskih umetnosti - Čigoja štampa, str. 9-10. 
čoveka kao socio-kulturnog subjekta. S tim u vezi, u nastavku teksta sledi osvrt na kulturu, ali i na baštinu kao njen naročito važan aspekt, a sve to u nameri da se stane na put aktuelnim dehumanizujućim pseudokulturnim pojavama.

\section{Ukratko o kulturi i baštini}

Polazeći od stava da kultura predstavlja specifičan set duhovnih, intelektualnih i emocionalnih karakteristika društva ili društvene grupe, te da pored umetnosti i književnosti, obuhvata i životni stil, načine zajedničkog življenja, vrednosne sisteme, tradicije i verovanja ${ }^{7}$, te tome dodajući da u preambuli Ustava UNESCO-a stoji da ljudsko dostojanstvo zahteva širenje kulture i obrazovanja s ciljem pravde, slobode i mira, kao i da je dužnost svih naroda da je ispune u duhu uzajamnog pomaganja, jasno je koliko kultura predstavlja relevantan faktor za čoveka kao društvenog subjekta. Nadalje, kultura se određuje i kao „ukupnost materijalnih i duhovnih vrijednosti koje je stvorio čovjek u svojoj društveno-historijskoj praksi u svrhu savladavanja prirodnih sila, razvoja proizvodnje i rješavanja društvenih zadaća"s. Dakle, ona obuhvata kako sredstva za proizvodnju i materijalne tvorevine tako i dostignuća nauke, umetnosti i filozofije, te morala i običaja, a čime se potvrđuje ne samo kao relevantan, nego i kao krajnje kompleksan činilac društva. Stvorena od strane čoveka, kultura je istovremeno ono zahvaljujući čemu čovek uistinu biva čovekom, te je samim tim više nego osnovano kulturu označiti kao za čoveka nužnu pojavu.

Kultura je, dakle, proces humanizacije čoveka i njegovog sveta, ali ona se može razvijati jedino ako nije ometana i ako joj se ne omeđavaju granice. Međutim, to ne znači da se samo za kulturu može zahtevati apsolutna sloboda, već da kultura može da prizna samo sopstvene unutrašnje granice koje se nalaze u kriterijumima kulturnog stvaralaštva koji su kako scijentistički tako i humanistički. Prema rečima Zagorke Golubović, idejna funkcija kulture se odnosi na "formiranje određenih stavova, pogleda na svet, određene 'životne filozofije', za koje pojedinci dobijaju podsticaje u svojoj kulturi, ali mogu slobodnim izborom da se opredeljuju između

7 Ova definicija je u skladu sa zaključcima Svetske konferencije o kulturnim politikama (MONDIACULT, Meksiko Siti, 1982), Svetske komisije o kulturi i razvoju (Our Creative Diversity, 1995) i Međuvladine konferencije o kulturnim politikama za razvoj (Stokholm, 1998).

8 Opća enciklopedija jugoslavenskog leksikografskog zavoda (tom 3), Zagreb: Jugoslavenski leksikografski zavod, 1967, str. 693. 
različitih alternativa“9 ${ }^{\prime \prime}$ Pomenuta idejna funkcija kulture ima karakter saznajnovrednosne usmerenosti i to bez ikakvih pretenzija da preuzme primat. Suprotno tome, ideološke funkcije ideologizirane kulture, konstatuje Golubovićeva, deluju represivno i to kako $u$ odnosu na individue tako i u odnosu na istinsku kulturu. „Ideologizacija je u stvari dogmatsko, jednostrano nametanje jednog shvatanja i zahtev da se celokupno kulturno stvaralaštvo podredi tom shvatanju i stavi u njegovu službu. ${ }^{\prime 10}$ Sistem(at)ske prakse potiskivanja idejne funkcije kulture i to u korist onih ideoloških, a osmišljene i sprovođenje od strane vodećih interesnih grupacija i danas su jednako zastupljene, s tim da mediji neretko predstavljaju vodeće mehanizme na koje se pomenute grupacije oslanjaju. Navedene prakse za svoj ishod imaju potiskivanje istinske kulture (a samim tim i baštine) u korist najrazličitijih pseudokultura.

Kada je u pitanju reč „baština“, malo je onih koji su upoznati sa značenjem njenog staroslovenskog korena (bašta kao otac), a iz čega proizilazi da je baština, naprosto, očevina. Pored toga, bašta u reči baština jeste turcizam i znači vrt. Ipak, iako bi dovođenje bašte-kao-vrta (koja nam je hronološki i kulturološki bliža) u etimološku vezu sa baštom-kao-očevinom predstavljalo grešku, to ne znači da ova homonimna relacija ne može da bude od koristi za razumevanje pojma baštine. UNESCO definiše baštinu kao „ono što smo nasledili iz prošlosti, ono što živimo danas i ono što predajemo narednim generacijama“, odnosno kao „poklon iz prošlosti za budućnost"11. Uz termin baština često se koristi pridev kulturna, te se tako kultura pojavljuje kao ono što može da bude od posebnog značaja za rasvetljavanje ovog termina. Prema Sloterdijku, kultura je „umješnost da se uspostave oaze, $\mathrm{tj}$. da se uspostave mjesta gde se svjesno radi na gradnji onoga što jedno drugom odgovara"12. Pored stava da kultura predstavlja pokušaj čoveka da uspostavi harmonično stanje koje bi bilo što sličnije prirodi, u humanističkoj tradiciji sintagma "nesavršen vrt" koju je prvi upotrebio Montenj postaje opšta metafora čovekovog kulturnog postojanja. Polazeći od Todorovog određenja nesavršenog vrta kao mesta na "kojem učimo da od prolaznog načinimo večno", te "na kojem se slučajnost susreta pretvara u životnu nužnost ${ }^{113}$, Popadić iznosi

9 Golubović, Z. (2011).„Ideologizacija kulture kao jedan vid otuđenja“ u: Kučinar, Z. (ur.) Protiv zabrana. Razgovor "Socijalizam i kultura" Filozofsko društvo Srbije 1969. Beograd: Službeni glasnik, str. 31.

10 Isto delo, str. 30.

11 World Heritage Information Kit, Paris: UNESCO World Heritage Centre, 2008, str. 5.

12 Sloterdijk, P. (1991).„Pariski aforizmi o racionalnosti“ u: Šarčević, A. (ur.) Filozofija u vremenu. Sarajevo: Svjetlost, str. 103.

13 Todorov, C. (2003). Nesavršeni vrt. Beograd: Geopoetika, tekst sa korica knjige. 
stav da je baštinu moguće posmatrati kao „plod nesavršenog vrta“ ${ }^{14}$ koji nudi mogućnost spoznaje.

Pojam baštine $u$ širem humanističkom okviru dobija značenje trezora zapamćenih (ne)materijalnih nosilaca vrednosti i normi iz prošlosti koje nisu uvek u saglasju sa svojstvima savremenog konteksta u kojima se baštine, kao ni sa preferencijama pojedinaca koji in baštine. Iz tog razloga, baštinu je moguće posmatrati na više načina: kao utemeljenje, teret, opravdanje i konačno, kao orijentaciju. Najpre, baština kao utemeljenje nije ništa drugo do pokušaj čoveka da obezbedi svedočanstva za vlastiti identitet; to je onaj kutak sveta u kojem se čovek prepoznaje. Ali, baština je i nešto što ograničava, te što čoveka oblikuje na način koji može i da mu se ne dopada, a usled čega nastoji joj se odupre. Baština je neretko korišćena i kao opravdanje, te je stoga neophodno istaći da je baština resurs, a njena upotreba očekivana situacija; pri tome, gde je upotreba, teško da se može izbeći i zloupotreba. Baština kao orijentacija treba da posluži čoveku radi boljeg razumevanja, ali i organizovanja sveta.

Humanistički model odnosa čoveka i baštine pokazuje se kao naročito važan. Upravo je humanizam neraskidivo povezan sa poimanjem čoveka, te je samim tim i baština njegovo nezaobilazno sredstvo u nastojanjima da spozna čoveka. Pri tome, neophodno je praviti razliku između humanizma u opštem i užem kontekstu. Opšti koncept humanizma obuhvata identitetsku, antagonističku i oportunističku kategoriju, te kao filozofija čoveka ima prednost u odnosu na prethodno iznete modele odnosa čoveka i baštine. Ali, s obzirom na to da humanizam u svom prvobitnom smislu predstavlja studije klasičnih (pre svega antičkih) starina, istome se ne može dati prioritet. S tim u vezi, Popadić polazi od svakodnevnog humanizma kao onog stupnja humanizma koji čoveku pruža mogućnost da razume realnost baštine, njenu dvostruku dimenzionalnost, kao i njen višestruki karakter (kao utemeljenja, tereta, opravdanja i orijentacije).,Baština stoga nije samo svedočanstvo o nekoj drugoj realnosti u odnosu na ovu našu; baština je svedočanstvo o transformaciji realnosti. A naročito o transformaciji svakodnevice, kao stupnja realnosti. ${ }^{\prime 15}$ Pri tome, baština kao plod nesavršenog vrta je i svedočanstvo o nesavršenstvu i transformacijama nesavršenstva iz jednog oblika u drugi.

Potrebno je skrenuti pažnju i na to da je markiranje i rasvetljavanje različitih socio-kulturnih konteksta od naročite važnosti za ispravno tumačenje celovitosti baštine, odnosno za razumevanje kako njene strukturalnosti tako i njene potrebe za integralnom interpretacijom. Drugim rečima, budući da određenu baštinu grade različiti konteksti (istorijski, verski, arhitektonski i dr.), od naročite je važnosti

14 Popadić, M. (2012). Čiji je Mikelanđelov David? Baština u svakodnevnom životu. Beograd: Centar za muzeologiju i heritologiju Filozofskog fakulteta, str. 19.

15 Isto delo, str. 33. 
ne samo uzimanje u obzir, već i valjano sagledavanje svih tih konteksta, a radi postizanja što potpunijeg uvida u bit same te baštine. Na ovom mestu valja se pozvati i na sledeću konstataciju Alaide Asman:

„Istorija se ne skladišti samo u arhivima naučnih institucija, nego se, uz veliki trud, inscenira i u pomenima, hodočašćima, mimohodima, svečanim govorima, statuama i nacionalnim spomenicima. Tome treba dodati i festivale i tableaux vivants, muzeje i istorijske slike, narodne pesme i slike koje se koriste za teatralizaciju istorije. Svi ovi istorijski žanrovi stvaraju i obrađuju istorijske mitove, simboličke jedinice nacionalnog pamćenja. Kod takvog tumačenja istorije na delu nije istorijska svest istorijske nauke, nego živo sećanje savremenika na istoriju. Ako iz konteksta istorijske svesti treba da pređu u kontekst nacionalnog pamćenja, istorijski podaci moraju se materijalizovati i kondezovati u čvrste simbole." ${ }^{\prime 16}$

U svemu tome, (savremeni) mediji mogu da budu od naročite koristi, ali i da se pokažu kao kontraproduktivni. Pored toga što mogu da predstave prošlost i pomognu u njenom razumevanju, mediji jednako mogu da imaju udela i u njenom insceniranju. Problem nastaje onda kada se medijski sadržaji koji se tiču konkretne baštine posmatraju van odnosa sa njihovim materijalnim nosiocicem, odnosno kada putem medija plasirane informacije postanu samodovoljne i počnu da formiraju sopstvenu realnost. Jezik takve realnosti tada nije jezik baštine, već jezik propagande koji neretko ima manipulativni karakter. Potrebno je napomenuti i da sve zatupljenija industrija nasleđa lukrativno pretvara kulturno nasleđe u robu pri čemu mediji predstavljaju njene vodeće instrumente. Zapravo, industrija nasleđa u sadejstvu sa "kulturnim turizmom“ nesumnjivo predstavlja najvidljiviji aspekt (zlo)upotrebe baštine. Učestvovanje medija u prevrednovanju i promociji određenih elemenata prošlosti koji su kao nosioci informacija u protivrečnosti sa ustanovljenom istorijskom realnošću nije ništa drugo do potvrda za svođenje tih istih medija na mehanizme dezavuisanja memorijske matrice, a time i same baštine. Iz tog razloga je važno imati na umu sledeću Popadićevu konstataciju:

„U Bibliji, u Knjizi Propovednikovoj, postoje ovi stihovi: '... svaka stvar pod nebom ima svoje vreme; ... vreme kad se obara i vreme kad se gradi' (Prop. 3.1 ; 3, 3). Drugačije nije ni sa baštinom. No, tu treba biti obazriv. U slučaju očuvanja patrimonijuma vreme 'obaranja' može postati vreme 'građenja' i obratno. Zašto? Zato što vreme baštine i vreme čoveka (...) nije isto. Baština je ono što pretrajava vreme, a čovek to, ipak, nije u stanju. Otuda i njegova svakodnevna briga o svedočanstvima..17

U nastavku teksta sledi preispitivanje odnosa medija i kulture s namerom da se (re)definiše uloga medija u promociji i popularizaciji istinske kulture, a time i baštine kao njenog bitnog aspekta. Naročita pažnja biće posvećena i studiji

16 Asman, A. (2002). Rad na nacionalnom pamćenju. Beograd: Svetovi, str. 54.

17 Popadić, M. (2012). Čiji je Mikelanđelov David? Baština u svakodnevnom životu, str. 53. 
slučaja koja markira i razmatra neke od segmenata (ne)materijalnog kulturnog nasleđa Sremskih Karlovaca, a uz apostrofiranje medija kao njihovih (in)direktinih i produktivnih promotera. Time se nastoji skrenuti pažnja na pozitivne aspekte nadogradnje odnosa između medija i kulturne baštine, a putem sprovođenja kako medijskog tako i kulturnog zaokreta.

\section{Mediji i kultura}

Polazeći od činjenice da je savremeni čovek istovremeno kako kreator tako i produkt masovne kulture, te da mu kao takvom istinska kultura nije naročito bliska, sasvim osnovano se može zaključiti da kultura u pravom smislu te reči sve manje predstavlja određujući faktor za čovekovo konstituisanje, egzistiranje i interakciju sa drugima. No, ukoliko se ima u vidu da je upravo kultura ono zahvaljujući čemu čovek uistinu biva čovekom utisak koji se neminovno nameće jeste da savremeni čovek nije ništa drugo do redukovana, pa čak i degradirana pojava sa upitnim stepenom razvijenosti sopstvenih potencijala. Sve ovo svedoči o krajnje problematičnom karakteru aktuelnih socio-kulturnih fenomena koje (in) direktno deluju na čoveka, te imaju značajnog udela u njegovom životu. Pri tome, kao naročito zabrinjavajuće u okviru ovog teksta su izdvojene pseudokulture kao bitni aspekti masovne kulture.

Prema Deboru savremeno kapitalističko društvo je postalo društvo spektakla kojim dominiraju slike; u pitanju je koncept spektakla koji se odnosi na novo doba u razvoju kapitalizma gde je sistem zasnovan na proizvodnji robe prerastao u sistem organizovan oko proizvodnje i konzumiranja spektakularnih slika. Spektakl u Deborovom tumačenju nije ništa drugo do "konkretizovana inverzija života"18; on ne označava samo vizuelne predstave sveta, već i ideologiju koja je oblikovala te predstave. Kultura spektakla nije ništa drugo do sastavni segment šire, masovne kulture i društva u okviru kojeg centralnu preokupaciju predstavlja potrošnja. Luri ističe da je potrošačka kultura u velikoj meri poprimila odlike materijalne kulture s obzirom na to da se životni stilovi kupuju i prodaju, dok je sreća proporcionalna materijalnom bogatstvu. Potrošačka kultura, prema ovoj teoretičarki, predstavlja način na koji ljudi koriste ili pak menjaju stvari radi zadovoljenja vlastitih potreba. Robe se danas koriste „kao da su umetnička dela, slike ili znaci, kojima se bavimo kroz procese fantazije, igre, sanjarenja i stvaranja slika"19.

18 Debor, G. (2003). Društvo spektakla. Beograd: Porodična biblioteka br. 4, anarhija/blok 45, str. 9.

19 Lury, C. (1996). Consumer Culture. New Brunswick and New Jersey: Rutgers University Press, str. 77-78. 
Kada je reč o medijskoj kulturi, potrebno je naglasiti da je i njoj svojstvena forma spektakla budući da je gotovo svaki proizvod pomenute kulture utemeljen u spektakularnom. Kelner smatra da je medijska kultura kao preovlađujući oblik kulture u savremenom društvu zamenila klasične oblike kulture koji su nekada bili u središtu pažnje, te postala dominantni oblik socijalizacije. Prema ovom teoretičaru "medijska kultura stvara izrazito snažne slike i prizore identifikacije koji mogu direktno da utiču na publiku“20. Kelner sugeriše i da se medijska kultura ne bavi samo segmentima realnog života, već i da pruža materijal za fantazije i sanjarenja, a time i oblikovanje mišljenja i ponašanja, kao i konstituisanje najrazličitijih identiteta.

Jedan od najznačajnijih elemenata medijske (a samim time i masovne kulture čiji je ona bitni segment) jeste zabava, dok indikator da upravo ona preovlađuje kako u kulturi tako i u društvu jeste činjenica da ozbiljne ideje i teme, ozbiljna dela i ozbiljni ljudi ne dobijaju pažnju i poštovanje jer se gotovo nigde ne uvažava nečiji istinski doprinos, nego isključivo zabavna vrednost. Na ovom mestu bi se sasvim osnovano moglo reći da supremacija kulture zabave danas predstavlja globalni fenomen koji precizno odslikava duh vremena u kojem živimo. Odbojnost prema svemu što odstupa od imperativa zabavnog, lagodnog i glamuroznog na sociokulturnom planu za svoju konsekvencu ima razočaranje i revolt usled suočavanja sa činjenicom da medijske predstave stvarnosti imaju veoma malo veze sa onim realnim. Iz tog razloga, hiperkomercijalizovana zabava, medijski spektakli, kultura potrošnje itd. završavaju u ispraznom populizmu i trenutnom hedonizmu, a što onemogućava kritičko i konstruktivno preispitivanje onog realnog.

Utisak koji se na osnovu rečenog nameće jeste da napredovanje masovne kulture potrošnje, spektakla, zabave itd., za svoju konsekvencu ima potiskivanje istinske kulture, te dovođenje u pitanje njene neophodnosti kako za savremeno društvo u celini tako i za društvene subjekte ponaosob. Kultura se usled toga sve manje shvata kao polje koje je od naročite važnosti za lični razvoj pojedinca, a sve više kao teret od kojeg se „oslobođenje“ pronalazi u trivijalnostima utilitarnih pseudokultura. Budući da u njihovoj promociji i popularizaciji velikog udela imaju upravo mediji, jasno je da se zatečeno stanje stvari ne može prevazići ukoliko se istovremeno ne bude radilo na izvođenju kako kulturnog tako i medijskog zaokreta. Na ovom mestu je važno naglasiti da se pomenuti zaokreti nalaze u međusobnom sadejstvu i to na način da zaokret u kulturnoj sferi neminovno vodi i ka zaokretu u medijskog sferi (i obrnuto). No, iako iz zaokreta u kulturoj sferi neminovno proizilaze benefiti i po medijsku sferu to svakako da ne znači da je taj isti zaokret sam po sebi dovoljan za obe sfere. Drugim rečima, svaka sfera zahteva vlastiti zaokret koji će biti primarno primenjen na njoj svojstvene okvire,

20 Kelner, D. (2004). Medijska kultura. Beograd: Clio, str. 182. 
ali ono što je za očekivati jeste da će se pozitivni efekti jednog takvog zaokreta neminovno odraziti i po drugu sferu. Nadalje, promene nastale izvođenjem navedenih zaokreta zahvatiće i društvo u celini, a čime će se obezbediti neophodni preduslovi za njegov dalji razvoj.

Kritičko promišljanje fenomena medija, kulture i baštine, kao i njihovog međusobnog odnosa koje je sprovedeno u okviru ovog rada razotkriva, pre svega, aktuelne zloupotrebe medija u cilju promocije i popularizacije pseudokultura, dok se u nastavku teksta nastoji skrenuti pažnja na mogućnost redefinisanja uloge medija i to na primeru Sremskih Karlovaca, a uz apostrofiranje medija kao (in)direktnih i produktivnih promotera (ne)materijalnog nasleđa ovog mesta. Polazeći od Fidlerove konstatacije da su „novi vidovi medija uvek uticali na društva i preobražavali ih", ali i napomene da "da li se ishod smatra dobrim ili lošim, dobrim delom zavisi od tačke gledišta ocenjivača" ${ }^{\prime 2}$, u okviru ovog rada se nastoje izbeći zamke subjektivizma, i to putem sagledavanja izabrane problematike iz što više različitih perspektiva. S tim u vezi, medijima se ne pristupa kao fenomenima čije su implikacije po socio-kulturni kontekst u okviru kojeg deluju a priori negativne. Mediji se, pre svega, razumeju kao pojave koje u sebi sadrže kako pozitivne tako i negativne potencijale, te se stoga odgovornost za krajnje ishode medijskih sadržaja i praksi pripisuje isključivo onima koji ih kreiraju i sprovode.

\section{Mediji kao promoteri baštine}

Polazeći od stava da baština kao bitni aspekt istinske kulture nije stvar samo muzeja, galerija, biblioteka, arhiva itd., kao i da se ista ne tiče samo onih koji su u teorijskom i/ili praktičnom smislu zaduženi da se brinu o njoj, u okviru ovog teksta baština se promišlja kao skup svedočanstava iz prošlosti koja na različite načine određuju svakodnevni život čoveka. Nadalje, imajući u vidu da (novi) mediji imaju zavidnog udela $u$ različitim vidovima zloupotrebe formi i sadržaja pretrajalih iz prošlosti, putem ovog teksta se nastoje ponuditi potencijalne smernice za (re)definisanje uloge tih istih medija, a u cilju afirmacije ne samo baštine, već i kulture uopšte. Dakle, (novi) mediji ne samo da se svode na instrumente u službi promocije i popularizacije pseudokultura, već se putem istih neretko sprovode i zloupotrebe kulturnog nasleđa pri čemu iza takvih praksi stoje, pre svega, vodeće političke i verske, ali i ekonomske interesne grupacije. lako negativno utiču kako na pojedince tako i na društvo u celini, čini se da su posledice zloupotreba baštine od strane političkih i verskih interesnih skupina daleko razornije od posledica industrije nasleđa koju čine ekonomske interesne grupe. Naime, revizije prošlosti,

21 Fidler, R. (2004). Mediamorphosis: razumevanje novih medija, str. 357. 
ali i sve zastupljenije revizije revizija smatraju se znatno problematičnijim od komercijalizacije kulture. Ipak, treba imati u vidu i da "tržišni ratovi“ mogu da stoje $\mathrm{u}$ istoj ravni sa društvenim previranjima, sukobima i u konačnom sa ratovima $u$ ime zaštite kulturnih, istorijskih i verskih „svetinja“, te da su daleko opasniji kada su istovremeno prožeti i ekonomskim i političkim preferencijama.

Interesne zloupotrebe nasleđa (a time i kulture) sprovode se, između ostalog, putem Interneta koji kao vodeće sredstvo reprezentacije olakšava mogućnost distribucije najrazličitijih sadržaja, ali istovremeno otežava mogućnost provere njihove validnosti i relevantnosti. Primeri pomenutih zloupotreba najočigledniji su u okviru internet prezentacija, te naloga na različitim društvenim mrežama iza kojih stoje političke stranke, kao i organizacije sa izrazito desničarskom orijentacijom. Međutim, pored otvorenih zloupotreba svedočanstava iz prošlosti, na Internetu su zastupljene i neadekvatne i/ili pak nedovoljno produktivne upotrebe nasleđa. Promišljanja o potonjem biće izvedena na primeru Sremskih Karlovaca. Pri tome, akcenat neće biti na kritičkom promišljanju medijskih zloupotreba nasleđa, već na nedovoljno produktivnoj upotrebi medija (konkretno Interneta) u cilju promocije baštine navedenog grada.

Imajući u vidu da identitet jednog grada, zasnovan na kontinuiranom baštinjenju različitih elemenata nasleđa, predstavlja svedočanstvo o trajanju grada, u nastavku teksta se na primeru Sremskih Karlovaca nastoji demonstrirati kako je moguće da se izbegne zamka koja proizilazi iz neadekvatnih medijskih praksi koje se bilo direktno bilo indirektno bave svedočanstvima iz prošlosti. Reč je o gradu sa izuzetno bogatim nasleđem koji se u poslednje dve decenije posvetio razvoju "kulturnog turizma" u cilju što produktivnije komercijalizacije tog istog nasleđa, ali pitanje koje se neminovno nameće jeste da li takav pristup (i u kolikoj meri) zaista doprinosi negovanju i afirmaciji istinske kulture? Nadalje, nemoguće je ne zapitati se i da li su na pravi način iskorišćeni potencijali medija radi promocije ovog grada i upoznavanja sa njegovom bogatom baštinom?

Imajući u vidu aktuelnu internet prezentaciju Turističke organizacije opštine Sremski Karlovci (u daljem tekstu TO) evidentno je da ista u prvom planu ima promociju turističkih sadržaja, a što je i za očekivati. Međutim, budući da se turistička ponuda ovoga grada zasniva na njegovom bogatom nasleđu, sporno je što samo nasleđe nije na adekvatan način prezentovano, kao i što su njegovi potencijali minimalno iskorišćeni. Na sajtu koji je izrađen 2017. godine nalazi se pet stranica (naslovna, virtuelni vodič, kulturna ruta, hrana i piće, te informacije), a ono što je već na prvi pogled uočljivo jeste da se isti ne ažurira redovno tj. da sadrži zastarele informacije. Tako, primera radi, zainteresovani za posetu Srem. Karlovcima preko sajta TO mogu da se upoznaju sa ugostiteljskom ponudom ovog grada, ali i da dobiju informacije u vezi sa restoranima koji više ne rade ili 
su otvoreni pod novim imenom, od strane novog vlasnika i sa bitno izmenjenom ponudom. Upitno je i zbog čega se putem sajta promovišu ugostiteljski kompleksi koji se nalaze van grada, a koji nemaju nikakve veze sa uslugama koje nudi TO, dok se, primera radi, seoska domaćinstva sa teritorije grada koja nude usluge smeštaja i domaće kuhinje nigde ne spominju. Jednako problematično je i to što se ne navode sva udruženja građana koja su aktivna na teritoriji Sremskih Karlovaca, kao ni manifestacije koje ta ista udruženja organizuju (a od kojih mnoge u svom fokusu imaju promociju nasleđa ovog grada).

Nadalje, na naslovnoj stranici, preciznije na samom dnu iste, nalazi se odeljak „O nama“ u okviru kojeg su navede usluge TO: razgledanje Sremskih Karlovaca u pratnji stručnih vodiča, poseta grobu Branka Radičevića na Stražilovu, obilazak manastira na Fruškoj gori, obilazak Petrovaradinske tvrđave, razgledanje Novog Sada, informacije vezane za turističku ponudu grada, rezervacija smeštaja u domaćoj radinosti i organizovanje degustacija vina u privatnim podrumima karlovačkih vinara. Kao novina posebno je izdvojena usluga pod nazivom „animacija kulturnog prostora“ u okviru koje kostimirani animatori dočekuju turiste $u$ centru grada i kroz turističku predstavu ih uvode $u$ istorijska zbivanja na prostoru Sremskih Karlovaca. Međutim, tek u sklopu stranice "kulturna ruta" potencijalni interesenti dobijaju nešto više informacijama o sadržajima ture "Karlovački mir" koja nije navedena među uslugama TO. U okviru njene podstranice „znamenitosti“ nalaze se više nego skromne informacije o Patrijaršijskom dvoru, Sabornoj crkvi, Karlovačkoj gimnaziji, česmi „Četiri lava“, Karlovačkoj bogosloviji, Kapeli mira, Rimokatoličkoj crkvi, Gornjoj crkvi, Donjoj crkvi, Magistratu, Bogoslovskom seminaru, Stefaneumu, spomeniku Vrangelu, Apoteci i Vidikovcu. Postavljene slike ovih znamenitosti ne ostavljaju naročito pozitivan prvi utisak budući da tek nakon što se uvećaju mogu da dočaraju lepote istih. Grob Branka Radičevića, kao i Stražilovo na ovom mestu se ne navode.

Stranica "virtuelni vodič" za svoju početnu odrednicu ima unutrašnjost TO, a što ima smisla ukoliko se ima u vidu da je reč o vodiču u okviru internet prezentacije TO. Međutim, kako je u pitanju promocija turističkih sadržaja Sremskih Karlovaca za očekivati bi bilo da virtuelni vodič za svoj "start" ima, primera radi, gradski trg. Pomenuti vodič ima i određenih manjkavosti usled toga što se internet prezentacija ne ažurira redovno, te se, primera radi, u sklopu istog može pogledati unutrašnjost Samarije koja je odavno zatvorena. Znatno bolji utisak u odnosu na virtuelni vodič ostavlja video materijal u okviru video galerije koja se nalazi na dnu naslovne stranice. Međutim, upitno je zbog čega pomenuta galerija sadrži svega dva promotivna spota, ali ne i film "Moje ime je Bisa"22 koji je proglašen za najbolji turistički film u kategoriji srpskog filma na međunarodnom festivalu turističkog i ekološkog filma SILA FEST 2013. Nadalje, mapa sa znamenitostima Sremskih

22 Film „Moje ime je Bisa“ (sa prevodom na engleski jezik) dostupan je na: https://www.youtube. com/watch?v=a1V6WeT7eUE 
Karlovaca koja može da bude od naročite koristi, uočljiva je tek nakon što se otvori foto galerija smeštena, opet, na dnu naslovne stranice. Ipak, razočaravajuće je što foto galerija, uz pomenutu mapu, sadrži svega četiri fotografije Sremskih Karlovaca.

Interesantno je i da je turom „Karlovački mir" predviđen obilazak poslastičarnice „Belilo" poznate iz filma "Lajanje na zvezde”, a kako bi se uz interpretaciju vodiča oživele scene iz ovog poznatog produkta domaće kinematografije. No, budući da ovo nije jedina lokacija grada koja je poslužila za scenu nekog domaćeg filma ili TV serije, nejasno je zbog čega u ponudi TO ne postoji tura koja bi za svoju temu imala, primera radi, „Sremski Karlovci na filmu i televiziji“. Važno je, takođe, naglasiti i da Sremski Karlovci nisu bili inspirativni samo za filmsku, već i za čitav niz drugih umetnosti, te da postoji zavidno umetničko nasleđe kojim se bilo direktno bilo indirektno promoviše ovaj grad. Ipak, TO u ovome ne vidi potencijal, te sami tim „kulturni turizam" ne pokušava da bazira na ovom vidu nasleđa i njegovoj promociji.

\section{ZAKLJUČNA RAZMIŠLJANJA}

Budući da se svet (novih) medija pokazao kao konstitutivan za shvatanje same stvarnosti, evidentno je i da je čovekovo poimanje realnosti pod uticajem tih istih medija u znatnoj meri promenjeno. Bitno je naglasiti i da su sa promenama u doživljaju realnosti neminovno nastupile i promene u doživljaju kulture, kao i baštine. S tim u vezi, ovim radom se nastojalo pokazati da mediji neretko imaju udela u marginalizaciji, ali i u degradaciju onoga što se smatra kulturom u pravom smuislu te reči, a kao posledica njihovih (zlo)upotreba. Naime, pored toga što mogu da predstave stvarnost i pomognu u njenom razumevanju, mediji jednako mogu da imaju udela i u njenom insceniranju. Isto važi i za medijske predstave kako kulture tako i baštine kao njenog bitnog segmenta. Problem, između ostalog, nastaje onda kada se medijski sadržaji koji se tiču konkretne baštine posmatraju van odnosa sa njihovim materijalnim nosiocem, odnosno kada putem medija plasirane informacije postanu samodovoljne i počnu da formiraju sopstvenu realnost. Upotreba medija radi umrežavanja fragmenata iz prošlosti koja za svoj ishod ima prevlast imaginarnog nad onim relanim pokazuje se kao naročito problematična i to, pre svega, u situacijama kada se jedan mali segment iz prošlosti koristi kao polazna osnova za (re)konstrukciju njene celine. Stoga je od naročite važnosti ne samo dekonstrukcija spornih medijskih praksi, već i adekvatna supstitucija onih praksi koje se negativno odražavaju po socio-kulturni kontekst u okviru kojeg su na delu. 
Međutim, pored medijskih zloupotreba, neophodno je imati u vidu i neadekvatne i/ili pak nedovoljno produktivne medijske predstave nasleđa. Promišljanja o potonjem u oviru ovog rada bila su izvedena na primeru Sremskih Karlovaca. Još jednom, akcenat nije bio na kritičkom promišljanju medijskih zloupotreba nasleđa, već na nedovoljno produktivnoj upotrebi medija (konkretno Interneta) u cilju promocije baštine navedenog grada. Imajući u vidu da nisu problematične samo zloupotrebe, već i nedakevatne upotrebe medija, putem ovog rada se nastojala skrenuti pažnja na neophodnost sprovođenje medijskog zaokreta u cilju (re)definisanja uloge medija. Pomenuti medijski zaokret istovremeno se razume i kao bitan preduslov za postizanje kulturnog zaokreta, a u cilju ponovne afirmacije istinske kulture.

Kada je reč o internet prezentaciji TO opštine Sremski Karlovci ista se smatra problematičnom usled toga što potencijale (ne)materijalnog nasleđa ovog grada ne koristi na pravi način. Preciznije, pomenuta prezentacija nudi više nego oskudne informacije o baštini Sremskih Karlovaca, te tako sve one koji su zainteresovani da ih posete uskraćuje za pravu sliku o ovom gradu. Umesto da iskoristi sve raspoložive mehanizme u cilju prezentovanja grada u što boljem svetlu, s veštim (pre)naglašavanjem svih njegovih kvaliteta, te jednako umešnim prikrivanjem njegovih manjkavosti, pomenuta prezentacija nije ništa drugo do očigledan primer nedovoljne iskorišćenosti potencijala Interneta. Utisak koji se stiče nakon detaljnog upoznavanja sa njenim sadržajem jeste odsustvo promišljenog i planskog prezentovanja ključnih segmenata kako materijalnog tako i nematerijalnog nasleđa Sremsih Karlovaca, a usled čega je izostalo koncipiranje i promovisanje najreprezentativnijih paketa u sklopu kulturnog turizma ovog grada. Nadalje, više nego očigledno je i nepostojanje združenog i produktivnog delovanja različitih struka za potrebe izrade pomenute prezentacije. $U$ prilog tome svedoče monotonost, oskudnost i selektivnost kao vodeće karakteristike pomenute prezentacije.

lako bi bilo za očekivati da se upravo internet prezentacija TO opštine Sremski Karlovci izdvaja po svome kvalitetu u odnosu na sve ostale internet sadržaje o ovom gradu, utisak koji se neminovno nameće je da ona ne ide u prilog niti kulturnom turizmu na kojem se bazira ponuda TO niti promociji bogatog nasleđa ovog grada. Uprkos tome što sam kulturni turizam (naročito u sadejstvu sa industrijom nasleđa) može da bude više nego problematičan, putem ovog rada se nastojala skrenuti pažnja na mogućnost postizanja produktivne bilo direktne bilo indirektne promocije (ne)materijalnog nasleđa i putem kvalitetno koncipiranih turističkih sadržaja. Međutim, upravo je na izdvojenom primeru pokazano da je u te svrhu neophodno najpre duboko promisliti, zatim osmisliti i u konačnom dosledno sprovesti kako medijski tako i kulturni zaokret. 


\section{LITERATURA}

1. Asman, A. (2002). Rad na nacionalnom pamćenju. Beograd: Svetovi.

2. Bodrijar, Ž. (1991). Simulakrumi i simulacija. Novi Sad: Svetovi.

3. Debor, G. (2003). Društvo spektakla. Beograd: Porodična biblioteka br. 4, Anarhija/blok 45.

4. Fidler, R. (2004). Mediamorphosis: razumevanje novih medija. Beograd: Clio.

5. Golubović, Z. (2011). „Ideologizacija kulture kao jedan vid otuđenja“ u: Kučinar, Z. (ur.) Protiv zabrana. Razgovor "Socijalizam i kultura" Filozofsko društvo Srbije 1969. Beograd: Službeni glasnik.

6. Kelner, D. (2004). Medijska kultura. Beograd: Clio.

7. Lury, C. (1996). Consumer Culture. New Brunswick and New Jersey: Rutgers University Press.

8. Opća enciklopedija jugoslavenskog leksikografskog zavoda (tom 3), Zagreb: Jugoslavenski leksikografski zavod, 1967.

9. Popadić, M. (2012). Čiji je Mikelanđelov David? Baština u svakodnevnom životu. Beograd: Centar za muzeologiju i heritologiju Filozofskog fakulteta.

10. Sloterdijk, P. (1991).„Pariski aforizmi o racionalnosti“ u: Šarčević, A. (ur.) Filozofija u vremenu. Sarajevo: Svjetlost.

11. Todorov, C. (2003). Nesavršeni vrt. Beograd: Geopoetika.

12. Vuksanović, D. (2007). Filozofija medija: ontologija, estetika, kritika, Beograd: Fakultet dramskih umetnosti - Čigoja štampa.

13. World Heritage Information Kit, Paris: UNESCO World Heritage Centre, 2008.

\section{Izvori:}

1. / Turistički film / i sl: Moje ime je Bisa (sa prevodom). You Tube, 15.09.2014.

Preuzeto sa: https://www.youtube.com/watch?v=a1V6WeT7eUE [10.08.2020.]

Рад је примљен: 27. август 2020. Прихваћен за објављивање: 31. август 2020.

Received: August 27, 2020.

Accepted: August 31, 2020. 